\title{
高品质陆地棉棉铃发育特点
}

陈 源 王永慧 肖 健 奕 娜张祥陈德华*

扬州大学江苏省作物遗传生理重点实验室, 江苏扬州 225009

摘 要: 以高品质棉杂交种科棉 3 号、常规种科棉 4 号为供试品种(常规品质棉苏棉 5 为对照), 于 2004-2005 年测 定棉铃的发育性状。结果表明, 高品质棉与常规品质棉明显不同, 前者铃较长、铃体积大、铃重高, 棉铃最大直径与 后者相似。科棉 3 号以花后 $10 \mathrm{~d}$ 内铃长增长快于常规品质棉、科棉 4 号则以花后 $10 \mathrm{~d} 、 21 \sim 30 \mathrm{~d}$ 快于常规品质棉; 高 品质棉铃最大直径的增长持续期短于常规品质棉, 且花后 $10 \mathrm{~d}$ 内增长慢; 高品质棉在花后 $20 \mathrm{~d}$ 内铃体积的增大高于 常规品质棉, 尤其以花后 11 20 d 增长更快; 科棉 3 号在开花后 $10 \mathrm{~d}$ 后铃重增长快于常规品质棉, 科棉 4 号则表现在 开花后 $20 \mathrm{~d}$ 前快于常规品质棉。说明以铃长为重要指标进行高品质类型棉花品种选育、以棉铃体积和铃重提高为载 体进行高产优质栽培调节是关键技术。

关键词: 高品质陆地棉; 棉铃发育; 铃长; 铃直径; 铃体积; 铃重

\section{Boll Development Characteristics for High-Quality Upland Cotton Cultivars}

\author{
CHEN Yuan, WANG Yong-Hui, XIAO Jian, LUAN Na, ZHANG Xiang, and CHEN De-Hua*
}

Jiangsu Provincial Key Laboratory of Crops Genetics and Physiology, Yangzhou University, Yangzhou 225009, China

\begin{abstract}
The objective of this study was to investigate the boll development characteristics of high-quality cotton cultivars. Two cultivars of high quality upland cotton, including hybrid Kemian 3 and conventional Kemian 4, with the conventional fiber quality cultivar Sumian 15 as control were planted on the farm of Jiangsu Provincial Key Laboratory of Crops Genetics and Physiology of Yangzhou University from 2004 to 2005. The results showed that the boll development characteristics were different between high-quality upland cotton and the conventional cotton. In comparison to the control, high quality cotton had longer boll length, similar boll diameter, bigger boll volume and higher boll weight. Kemian 3 had faster increase of the boll length within 10 days post anthesis (DPA), Kemian 4 within both 10 days and 20 to 30 DPA, and both of high quality cotton had slower expansion of the boll diameter within 10 DPA, and shorter expansion period of boll diamete, as well as bigger increase of the boll volume within 20 DPA, especially from 10 to 20 DPA. The boll weight increase was higher after 10 DPA for Kemian 3, and before 20 DPA for Kemian 4. The results suggested that boll length is the important index for high quality fiber cotton breeding and developing bigger and high-weight bolls is the key way in the cultivation for high lint yield and good fiber quality.
\end{abstract}

Keywords: High fiber quality upland cotton; Boll development; Boll length; Boll diameter; Boll volume; Boll weight

高品质棉由于其纤维长度在 $30 \mathrm{~mm}$ 以上, 比强 度在 $35 \mathrm{cN} \mathrm{tex}{ }^{-1}$ 以上, 马克隆值 4.1 4.4, 纤维品质 优于常规陆地棉, 其原棉在纺织上可代替海岛棉纺 织高支纱和精梳纱, 显著降低成本, 受到纺织部门 的普遍认可, 目前在生产上呈供不应求的局面 ${ }^{[1-3]}$ 。 高品质棉品种是由陆地棉和海岛棉杂交选育而成, 其棉铃的发育与常规棉明显不同 ${ }^{[4-5]}$, 前人对海陆杂 棉研究较多, 一般认为海陆杂交棉能够有效体现杂
交优势, 纤维品质得到改善, 但产量性状况不及陆 地棉，主要表现为铃小、衣分低、不孕籽率高、结 铃率强 ${ }^{[6-10]}$ 。由于杂交育种技术的改进 ${ }^{[11-12]}$, 经过不 同种质资源的多代篮选，现阶段选育出的高品质棉 品种(系)的产量性状有所突破, 主要表现铃重提高、 铃型长粗比大、结铃率高等特点。前人对高品质棉 的棉铃发育主要集中在棉铃最终的定性描述上，而 对高品质棉铃的发育特点及动态过程系统研究报道

\footnotetext{
本研究由农业部生物新品种培育重大转基因专项(2009ZX08013-011B，2009ZX08013-014B)，江苏省农业科技自主创新资金[cx(08)114]，江苏 省三项工程项目 $[\mathrm{sx}(2007) 110]$ 和江苏省青蓝工程和扬州大学新世纪学术带头人基金资助。

*通讯作者(Corresponding author): 陈德华, E-mail: dehuachen2002@yahoo.com.cn, Tel: 0514-87979357

第一作者联系方式: E-mail: nxx@yzu.edu.cn

Received(收稿日期): 2010-01-29; Accepted(接受日期): 2010-04-19.
} 
较少。本文就高品质棉棉铃发育动态特点进行研究, 以期为其品种选育和促进棉铃发育、实现高产保优 栽培提供依据。

\section{1 材料与方法}

\section{1 试验设计}

2004-2005 年在扬州大学试验地种植高品质棉 品种科棉 3 号(杂交种)和科棉 4 号(常规种), 以常规 品质棉品种苏棉 15 为对照。试验小区面积 $40 \mathrm{~m}^{2}$, 每 公顷 27000 株, 按单因素随机区组设计, 重复 3 次。 试验地为砂壤土, 土壤含有机质 $1.68 \%$ 、水解氮 $134.7 \mathrm{mg} \mathrm{kg}^{-1}$ 、速效磷 $25.2 \mathrm{mg} \mathrm{kg}^{-1}$ 、速效钾 $80.6 \mathrm{mg}$ $\mathrm{kg}^{-1}$ 。两年均采用育苗移栽, 4 月 3 日播种, 5 月 13 日移栽，两年栽培管理措施相同，氮肥(尿素) 300 $\mathrm{kg} \mathrm{hm}^{-2}$, 其中基肥占 $20 \%$, 花铃肥占 $65 \%$ (分初花 期和盛花期两次使用, 第一次花铃肥占 $18 \%$, 第二 次花铃肥占 $47 \%$ ), 桃肥占 $15 \%$; 磷肥 (过磷酸钙) $600 \mathrm{~kg} \mathrm{hm}^{-2}$, 基肥和第一次花铃肥各占 $50 \%$; 钾肥 (氯化钾) $375 \mathrm{~kg} \mathrm{hm}^{-2}$, 基肥和第一次花铃肥各占 $50 \%$, 各期氮、磷、钾肥均混合后施用; 在盛蕾、初 花、盛花和打顶后施用缩节安(DPC)化控, 用量分别 为 $15 、 30 、 45$ 和 $60 \mathrm{~g} \mathrm{hm}^{-2}$ 。田间其他管理措施按 高产要求进行。

\section{2 测定内容与方法}

试验于 7 月 20 27日对各处理中部内围果节(内 部第 1 2 果节)当日花, 分别于花后 $10 、 20 、 30 、 40$ 和 $50 \mathrm{~d}$ 取样测定棉铃的发育状况, 各处理每次取棉 铃 15 个, 计算其平均值。

以游标卡尺鲜样测量从铃基到铃尖的长度为棉 铃长度; 以游标卡尺鲜样测量棉铃横径的最大值为 棉铃直径; 用排水法测定棉铃体积; 将鲜样快速杀 青, 烘干至恒重为棉铃重。

\section{3 数据处理与统计分析方法}

运用 SPSS16.0 软件对棉铃发育动态两年平均 数据进行 $t$ 测验, $|t|<t_{0.05}(v=4)$ 。使用 Microsoft Excel 2003 软件作图; MATLAP 软件系统进行 Logistic 生 长曲线模拟。

\section{2 结果与分析}

\section{1 棉铃长度的变化}

图 1 表明, 高品质棉与常规品质棉铃长均随铃 龄增加。高品质棉品种的铃长明显长于常规品质棉 品种, 其中科棉 3 号 (Kemian 3) 铃长比苏棉 15
(Sumian 15)长 $0.65 \mathrm{~cm}$, 科棉 4 号(Kemian 4)比苏棉 15 长 $0.36 \mathrm{~cm}_{\text {。 }}$ 铃长主要在开花后 $0 \sim 30 \mathrm{~d}$ 快速增长, 其中又以 $0 \sim 10 \mathrm{~d}$ 增长最快。高品质棉品种与常规品 质棉品种相比, 科棉 3 号主要在花后 $0 \sim 10 \mathrm{~d}$ 铃长显 著增长, 科棉 4 号则在花后 $0 \sim 10 \mathrm{~d} 、 21 \sim 30 \mathrm{~d}$ 显著增 长。说明高品质棉杂交种花后 $0 \sim 10 \mathrm{~d}$ 铃长生长优势 明显, 高品质棉常规种则以花后 $0 \sim 10 \mathrm{~d} 、 21 \sim 30 \mathrm{~d}$ 铃 长生长优势明显, 但增长速度在花后 $0 \sim 10 \mathrm{~d}$ 显著低 于杂交种。

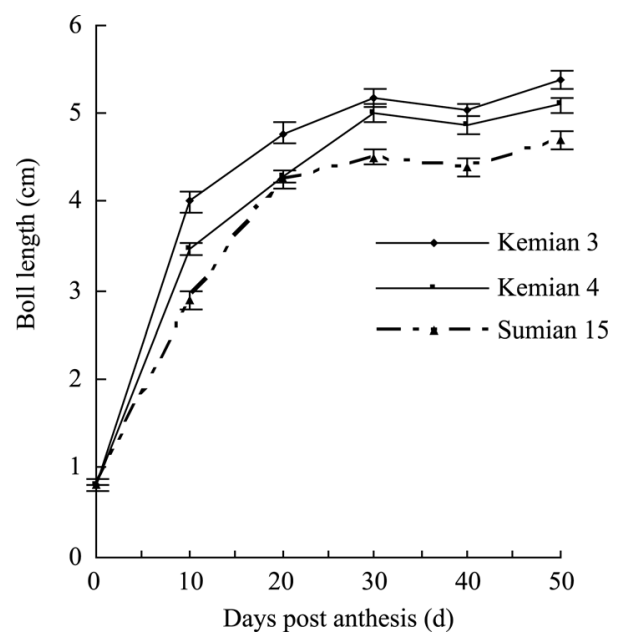

图 1 棉铃长度发育动态

Fig. 1 Development dynamics of boll length after anthesis

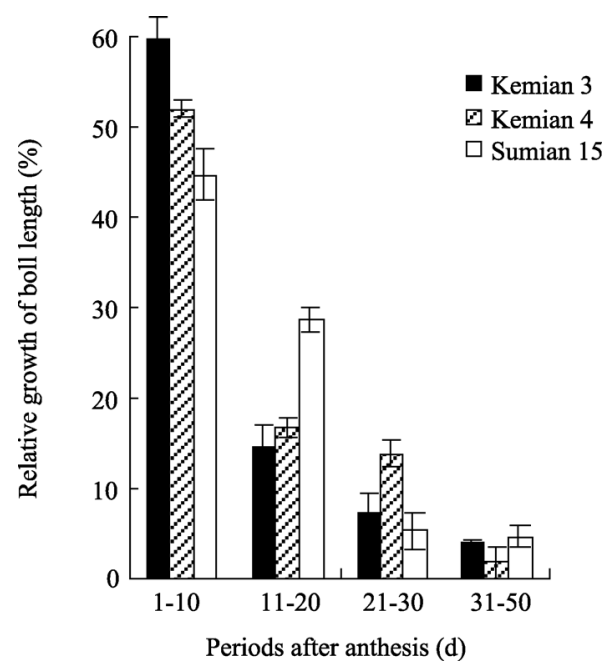

图 2 开花后棉铃长度相对增长量

Fig. 2 Relative growth of boll length after anthesis

铃长的相对生长量(图 2), 在花后 $0 \sim 10 \mathrm{~d} 、 11 \sim 20$ $\mathrm{d}$ 和 $21 \sim 30 \mathrm{~d}$, 科棉 3 号分别为 $59.67 \% 、 14.35 \%$ 和 $7.13 \%$; 科棉 4 号分别为 $52.02 \% 、 16.76 \%$ 和 $13.72 \%$; 苏棉 15 分别为 $44.67 \%$ 、28.61\%和 $5.19 \%$ 。花后 $0 \sim 10$ $\mathrm{d}$ 科棉 3 号的铃长相对生长量是苏棉 15 的 1.34 倍, 
科棉 4 号在花后 $21 \sim 30 \mathrm{~d}$ 是苏棉 15 的 2.64 倍。说明 高品质棉杂交种科棉 3 号在花后 $0 \sim 10 \mathrm{~d}$ 是铃长增长 的主要时期, 高品质棉常规种科棉 4 号在花后 $0 \sim 10$ $d 、 21 \sim 30 \mathrm{~d}$ 是铃长增长的主要时期。

铃长的增长符合 Logistic 生长曲线。苏棉 15 铃 长变化曲线方程为 $y=4.5544 /\left(1+4.6585 \mathrm{e}^{-0.2103 x}\right)\left(R^{2}=\right.$ $\left.0.9956^{* *}, n=6\right)$, 科棉 3 号铃长变化曲线方程为 $y=$ $5.0834 /\left(1+226.6891 \mathrm{e}^{-0.6735 x}\right),\left(R^{2}=0.9911^{* *}, n=6\right)$, 科棉 4 号铃长变化曲线方程为 $y=4.8118 /\left(1+56.0948 \mathrm{e}^{-0.4934 x}\right)$ $\left(R^{2}=0.9807^{* *}, n=6\right)$, 以上方程表明, 科棉 3 号的铃 长最长, 极限值达 $5.0834 \mathrm{~cm}$, 科棉 4 号铃长次之, 极限值为 $4.8118 \mathrm{~cm}$ 。铃长生长变化由快转慢的拐点 对照苏棉 15 在花后 $7.3 \mathrm{~d}$, 科棉 3 号在花后 $8.1 \mathrm{~d}$, 科 棉 4 号在花后 $8.2 \mathrm{~d}$, 进一步说明在花后 $0 \sim 10 \mathrm{~d}$ 是铃 长增长的主要时期。

\section{2 棉铃最大直径的变化}

图 3 表明, 高品质棉品种铃最大直径的变化随 铃龄呈先增加而至一定日龄后有所下降的趋势, 常 规品质棉则呈增加的趋势。高品质棉的直径最终与 常规品质棉相差不大。高品质棉铃直径快速增长期 主要在开花后 $0 \sim 20 \mathrm{~d}$, 其中又以花后 $0 \sim 10 \mathrm{~d}$ 增长最 快, 而常规品质棉铃直径增长在花后 $30 \mathrm{~d}$ 内。高品 质棉科棉 3 号铃直径增长在花后 $0 \sim 10 \mathrm{~d}$ 慢于常规品 质棉, 11 30 d 快于常规品质棉; 科棉 4 号则以花后 11 20 d 快于常规棉。说明高品质棉铃直径的增长持 续期短于常规品质棉。

棉铃直径的相对生长量(图 4), 在花后 $0 \sim 10 \mathrm{~d}$ 、 $11 \sim 20 \mathrm{~d}$ 和 $21 \sim 30 \mathrm{~d}$, 科棉 3 号分别为 $57.28 \% 、 26.19 \%$ 和 $6.28 \%$; 科棉 4 号分别为 $59.09 \% 、 27.97 \%$ 和 $1.86 \%$; 苏棉 15 分别为 $61.13 \% 、 15.60 \%$ 和 $2.44 \%$ 。进一步

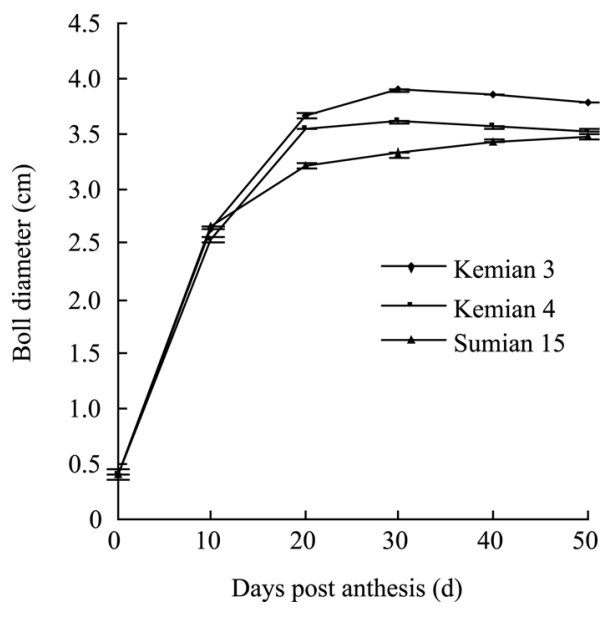

图 3 棉铃直径发育动态

Fig. 3 Development dynamics of boll diameter after anthesis

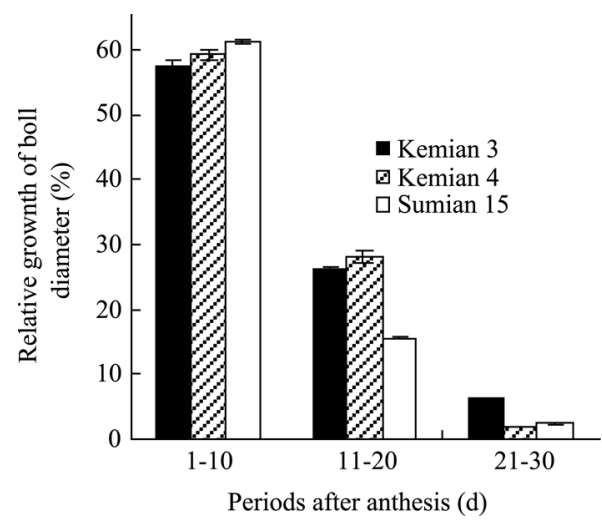

图 4 开花后棉铃直径相对增长量

Fig. 4 Relative grownth of boll diameter after anthesis

说明棉铃直径的增长主要集中在花后 $0 \sim 20 \mathrm{~d}$ ，但高 品质棉杂交种前期增长进程较慢, 而高品质棉常规 种和常规品质棉则较快。

棉铃直径的增长符合 Logistic 生长曲线。苏棉 15 符合曲线方程为 $y=3.4238 /\left(1+7.1535 \mathrm{e}^{-0.3155 x}\right)$ $\left(R^{2}=0.9961^{* *}, n=6\right)$, 科棉 3 号符合曲线方程为 $y=$ $3.8162 /\left(1+16.0366 \mathrm{e}^{-0.3562 x}\right)\left(R^{2}=0.9978^{* *}, n=6\right)$, 而 科棉 4 号的铃直径符合曲线方程为 $y=3.5646 /(1+$ $\left.17.0349 \mathrm{e}^{-0.3734 x}\right)\left(R^{2}=0.9996^{* *}, n=6\right)$ 。科棉 3 号、科 棉 4 号铃直径生长由快转慢的拐点分别出现在花后 $7.8 \mathrm{~d}$ 与 $7.6 \mathrm{~d}$, 而对照苏棉 15 出现在 $6.2 \mathrm{~d}$ 。以上分 析进一步说明, 高品质棉铃直径增长最快的时期为 花后 $20 \mathrm{~d}$ 前, 尤其是在花后 $0 \sim 10 \mathrm{~d}$ 内增长最快。

\section{3 棉铃体积的变化}

图 5 表明, 2 个不同类型的高品质棉品种铃体积 均随铃龄增加而增大。高品质棉的铃体积显著高于 常规品质棉, 其中科棉 3 号比苏棉 15 大 $5.63 \mathrm{~cm}^{3}$, 科棉 4 号比苏棉 15 大 $5.30 \mathrm{~cm}^{3}$ 。体积的快速增大主 要在开花后 0 20 d, 其中高品质棉以花后 11 20 d 增长最快, 常规品质棉则以花后 $0 \sim 10 \mathrm{~d}$ 增长最快。 高品质棉与常规品质棉相比, 科棉 3 号和科棉 4 号 都是在花后 $0 \sim 20 \mathrm{~d}$ 铃体积显著增大, 进一步说明高 品质棉在花后 $20 \mathrm{~d}$ 内铃体积增大优势明显。

花后 0 10 d、11 20d 和 21 30 d 铃体积相对增 长量(图 6), 科棉 3 号为 $39.60 \% 、 42.15 \%$ 和 $9.24 \%$; 科 棉 4 号分别为 $37.88 \% 、 45.96 \%$ 和 $8.21 \%$; 苏棉 15 分 别为 $39.71 \% 、 38.30 \%$ 和 $16.39 \%$ 。说明高品质棉铃 体积快速增长持续时间较短, 主要集中在花后 0 20 $\mathrm{d}$; 常规品质棉持续时间较长。由于高品质棉铃体积 高于常规品质棉, 显然高品质棉的体积增长速度快 于常规品质棉。 


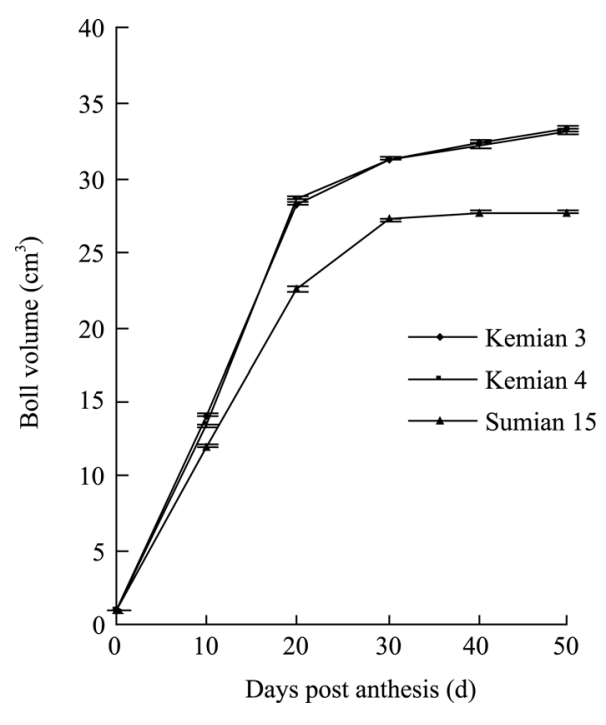

图 5 棉铃体积发育动态

Fig. 5 Development dynamics of boll volume after anthesis

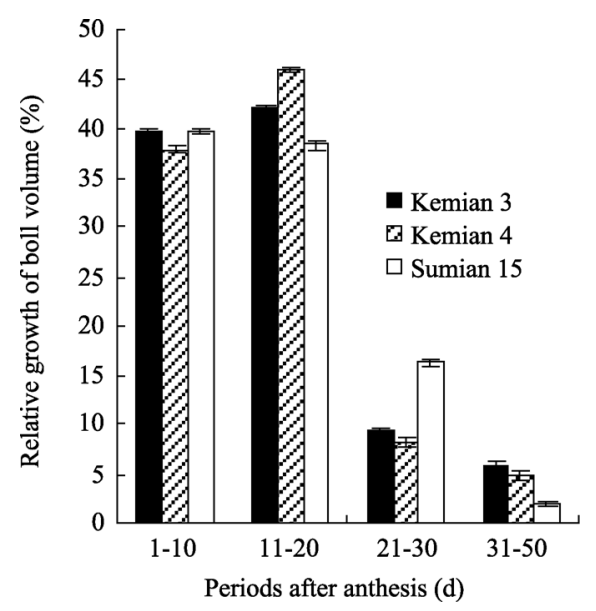

图 6 开花后棉铃体积相对增长量

Fig. 6 Relative grownth of boll volume after anthesis

铃体积增长符合 Logstic 生长曲线。苏棉 15 符 合曲线方程 $y=27.0887 /\left(1+12.2472 \mathrm{e}^{-0.2179 x}\right)\left(R^{2}=\right.$ $\left.0.9942^{* *}, n=6\right)$, 科棉 3 号符合曲线方程 $y=32.2479 /$ $\left(1+17.5334 \mathrm{e}^{-0.2540 x}\right)\left(R^{2}=0.9939^{* *}, n=6\right)$, 科棉 4 号 符合曲线方程 $y=32.0921 /\left(1+21.9327 \mathrm{e}^{-0.2712 x}\right)\left(R^{2}=\right.$ $\left.0.9963^{* *}, n=6\right)$ 。以上方程进一步表明高品质棉的棉 铃体积要显著高于常规品质棉。

\section{4 铃重的变化}

图 7 表明, 棉输重的变化随铃龄呈增加的趋势。 高品质棉的铃重高于常规棉, 其中科棉 3 号铃重比 苏棉 15 高 $0.77 \mathrm{~g}$, 科棉 4 号比苏棉 15 高 $0.54 \mathrm{~g}$ 。铃 重快速增长期都在开花后 11 30 d, 其中又以 11 20 $\mathrm{d}$ 增长最快。高品质棉与常规品质棉相比, 科棉 3 号 主要在花后 $11 \sim 30 \mathrm{~d}$ 和 $41 \sim 50 \mathrm{~d}$ 显著增长, 科棉 4 号 则以花后 $0 \sim 10 \mathrm{~d} 、 11 \sim 20 \mathrm{~d}$ 显著增长。说明高品质棉
杂交种和常规种铃重与常规品质棉的快速增长期不 同, 杂交种主要在花后 $10 \mathrm{~d}$ 以后, 常规种在花后 20 $d$ 前。

在花后 $0 \sim 10 \mathrm{~d} 、 11 \sim 20 \mathrm{~d}$ 和 $21 \sim 30 \mathrm{~d}$ 的铃重相对 增长量(图 8), 科棉 3 号分别为 $11.99 \% 、 41.31 \%$ 和 $28.96 \%$; 科棉 4 号分别为 $17.51 \% 、 48.50 \%$ 和 $19.66 \%$; 苏棉 15 分别为 $16.81 \% 、 39.29 \%$ 和 $28.31 \%$ 。说明与 常规品质棉相比, 铃重增长速度高品质棉常规种在 生育前期较快, 高品质棉杂交种在生育后期较快。

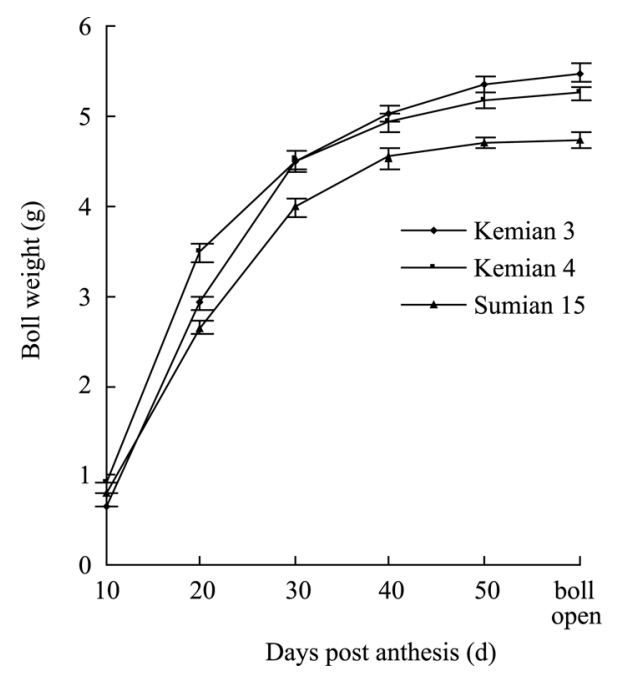

图 7 棉铃铃重变化动态

Fig. 7 Development dynamics of boll weight after anthesis

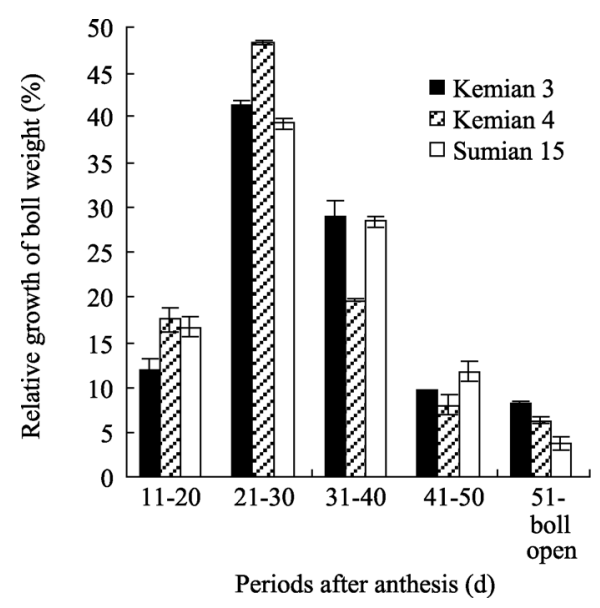

图 8 开花后棉铃铃重相对增长量

Fig. 8 Relative grownth of boll weight after anthesis

铃重的增长符合 Logistic 生长曲线, 苏棉 15 为 $y=4.6933 /\left(1+23.9597 \mathrm{e}^{-0.1683 x}\right)\left(R^{2}=0.9984^{* *}, n=6\right)$, 科棉 3 号为 $y=5.3292 /\left(1+35.0392 \mathrm{e}^{-0.1821 x}\right)\left(R^{2}=0.9962^{* *}\right.$, $n=6)$, 科棉 4 号为 $y=5.0841 /\left(1+31.4171 \mathrm{e}^{-0.2046 x}\right)$ $\left(R^{2}=0.9945^{* *}, n=6\right)$ 。科棉 3 号、科棉 4 号棉铃铃重 生长由快转慢的拐点分别出现在花后 $19.5 \mathrm{~d} 、 16.8 \mathrm{~d}$, 
而苏棉 15 在花后 $18.8 \mathrm{~d}$, 科棉 3 号、科棉 4 号和苏 棉 15 对照铃重的极限值分别为 5.3292、5.0841 和 $4.6933 \mathrm{~g}$, 以上方程进一步表明, 高品质棉杂交种和 常规种铃重高于常规棉, 但两者的快速增长期不同, 杂交种主要在前期，常规种在后期。

2.5 高品质棉铃长、铃最大直径对铃体积、铃重 的影响

如表 1 和表 2 所示, 棉铃铃长、铃直径与棉铃 体积的直接通径系数分别为 $p_{\text {铃长-体积 }}=0.6831$ 和 $p_{\text {铃直 }}$ 径-体积 $=0.3669$, 表明铃长对铃体积的影响高于棉铃 直径对棉铃体积的影响。 $p_{\text {朎长一朎重 }}=2.3083 、 p$ 铃直径-朎 重 $=0.2752 、 p_{\text {体积 }- \text { 铃重 }}=-1.7183$, 表明棉铃长度对棉铃 重的影响最大, 因此扩大棉铃长度有利于提高高品 质棉的铃体积与铃重。

表 1 棉铃长度 $\left(x_{1}\right)$ 、最大直径 $\left(x_{2}\right)$ 与棉铃体积 $(Y)$ 的通径分析

Table 1 Path-coefficient analysis between boll volume $(Y)$ and boll length $\left(x_{1}\right)$, boll diameter $\left(x_{2}\right)$

\begin{tabular}{lcc}
\hline \multicolumn{1}{c}{ 项目 Item } & $1 \rightarrow Y$ & $2 \rightarrow Y$ \\
\hline 棉铃长度 Boll length $\left(x_{1}, 1\right)$ & 0.6831 & 0.2794 \\
棉铃最大直径 Boll diameter $\left(x_{2}, 2\right)$ & 0.5201 & 0.3669 \\
\hline
\end{tabular}

表 2 棉铃长度 $\left(x_{1}\right)$ 、最大直径 $\left(x_{2}\right)$ 、棉铃体积 $\left(x_{3}\right)$ 与铃重 $(Y)$ 的通 径分析

Table 2 Path-coefficient analysis between boll weight $(Y)$ and boll length $\left(x_{1}\right)$, boll diameter $\left(x_{2}\right)$, boll volume $\left(x_{3}\right)$

\begin{tabular}{lccc}
\hline \multicolumn{1}{c}{ 项目 Item } & $1 \rightarrow Y$ & $2 \rightarrow Y$ & $3 \rightarrow Y$ \\
\hline 棉铃长度 Boll length $\left(x_{1}, 1\right)$ & 2.3083 & 0.1958 & -1.6539 \\
棉铃最大直径 Boll diameter $\left(x_{2}, 2\right)$ & 1.7575 & 0.2572 & -1.5241 \\
棉铃体积 Boll volume $\left(x_{3}, 3\right)$ & 2.2217 & 0.2281 & -1.7183 \\
\hline
\end{tabular}

\section{3 讨论}

高品质棉品种是由陆地棉和海岛棉杂交选育而 成的, 其铃形特点与海岛棉相似, 呈现铃较长的特点, 这与海岛棉的铃长符合加性-显性遗传模型有关 ${ }^{[13]}$ 。一 般研究认为, 棉铃在花后 $21 \mathrm{~d}$ 左右铃长度、铃横径、 种仁长度、单铃体积达到最大值 ${ }^{[5,14-16]}$, 高品质棉棉 铃发育虽与常规品质棉有相似特征 ${ }^{[8]}$, 铃重的增长 在花后 $30 \mathrm{~d}$ 内较快 ${ }^{[17-18]}$, 但其铃长、铃直径、铃体 积和铃重的快速增长期和增长阶段与常规品质棉有 所不同(图 1、图 3、图 5 和图 7)。与常规品质棉相 比, 高品质棉棉铃长在花后 $10 \mathrm{~d}$ 内生长优势明显, 棉铃直径的扩展主要是开花 $10 \mathrm{~d}$ 以后加快, 棉铃体 积的快速增大期集中在花后 $20 \mathrm{~d}$ 前, 高品质棉杂交 种铃重的快速增长期出现在开花 $10 \mathrm{~d}$ 以后、常规种 铃重的快速增长期出现在花后 $20 \mathrm{~d}$ 前。
棉铃发育过程包括棉铃体积的增大和内部物质 的充实。棉铃体积的增加主要表现为棉铃长度的增 加和棉铃直径的增大, 棉铃内部物质的充实主要体 现为棉铃重量的不断增加, 铃库越大, 越有利于调 动物质流向铃库, 促进铃重的提高。高品质棉的棉 铃直径与常规品质棉相差不显著, 通径分析表明铃 长对铃体积的影响最大(表 1), 棉铃长度对棉铃重的 影响最大(表 2)。因此在培育高品质棉时, 可以有目 的地选择直径大, 且铃较长的种质; 栽培中也应根 据高品质棉棉铃性状的形成特点, 尤其在铃长快速 增长期, 通过促进铃长的增长提高铃重。

\section{4 结论}

高品质棉铃长生长时间长、速度快, 棉铃体积 大、铃重高。应以铃长为重要指标进行高品质类型 棉花品种选育, 以棉铃体积和铃重提高为载体进行 高产优质栽培调节。

\section{References}

[1] He X-P(何旭平), Leng S-F(冷苏凤), Gi C-M(季春梅), Cheng $\mathrm{H}-\mathrm{L}$ (承泓良). Discussion on industrialization of the super quality cotton in Jiangsu province. China Cotton (中国棉花), 2001, 28(8): 6-8 (in Chinese)

[2] Wan S-A(万少安), Ren Q(任琪). Comparing and analysis of cotton fiber quality in China and foreign countries. China Cotton Process (中国棉花加工), 2007，(1)：27-28 (in Chinese with English abstract)

[3] Husodo H O. Spinner's perspective changing need. 11th Australian Cotton Conference, 2002. pp 25-33

[4] Xu L-H(徐立华), Li G-F(李国锋), He X-H(何循宏), Yang D-Y(杨德银). Surce-sink characteristics of “Kemian 1" with high quality. China Cotton (中国棉花), 2003, 30(11): 14-16 (in Chinese)

[5] Xu L-H(徐立华), Li G-F(李国锋), He X-H(何循宏), Yang D-Y(杨德银). Boll developmental characteristic of “Kemian 2" with high quality. Jiangsu J Agric Sci (江苏农业学报), 2003, 19(4): 218-222 (in Chinese with English abstract)

[6] Hua X-N(华兴鼎), Zhou H(周行), Huang J-Q(黄骏麒), Zhu S-L(朱绍琳), Yu S-J(俞淑娟), Zhang J-S(张建生), Liu X-M(刘 兴民). The use of heterosis in the interspecific $\mathrm{F}_{1}$ between $G$. hirsutum and G. barbadense. Acta Agron Sin (作物学报), 1963, 2(1): 1-24 (in Chinese with English abstract)

[7] Diao G-Z(フ光中), Huang Z-K(黄滋康). Utilization of heterosis between G. hirsutum and G. barbadense. Sci Agric Sin (中国农业 科学), 1961, 2(7): 49-50 (in Chinese with English abstract) 
[8] Qu J-M(曲健木). The study of heterosis utilization interspecific $\mathrm{F}_{1}$ in cotton. J Hebei Agric Univ (河北农业大学学报), 1962, 1(1): 15-18(in Chinese with English abstract)

[9] Marani A. Heterosis and inheritance of quantitative characters in interspecific crosses of cotton. Crop Sci, 1968, 8: 299-303

[10] Percy R G, Turcotte E L. Interspecific hybrid fiber characteristics of cotton altered by unconventional Gossypium barbadense L. fiber genotypes. Crop Sci, 1992, 32: 1437-1441

[11] Zhang Z-S(张正圣), Zhang F-X(张凤釒金), Xia Y-X(夏玉先), Wang S-Q(王秀全). Selective breeding of strain with long style in upland cotton and its heterosis utilization. Sci Agric Sin (中国农业科学), 1999, 32(4): 27-33 (in Chinese with English abstract)

[12] Zhang X-Q(张小全), Wang X-D(王学德). Preliminary study on heterosis of interspecific hybrid cotton $(G$. hirsutum $\times$ G. barbadense) based on cytoplasmic male sterility system. Cotton Sci (棉花学报), 2005, 17(2): 79-83 (in Chinese with English abstract)

[13] Cao X-C(曹新川), Kang Z-Y(康志钰), He L-R(何良荣), Mei Y-J(梅拥军), Hu S-L(胡守林). Genetic analysis of the boll traits in island cotton. Acta Agric Boreali-Occident Sin (西北农业学 报), 2006, 15(5): 65-68 (in Chinese with English abstract)

[14] Chen D-H(陈德华), Chen Y(陈源), Yang C-Q(杨长琴), He Z-P(何钟佩), Wu Y-K(吴云康). The effects on the boll weight and the source-sink characteristics in the coordination of nitrogen fertilizer and DPC in Bt cotton. Cotton Sci (棉花学报), 2002, 14(3): 147-150 (in Chinese with English abstract)

[15] Chu G-X(褚贵新), Sun J(孙杰), Diao M(フ明), Su Z-Y(苏子友), Liu T(刘涛), Shen Q-R(沈其荣). Study on characteristics of cotton boll development among cotton varieties from different areas in northern Xinjiang. Cotton Sci (棉花学报), 2002, 14(1): 17-21 (in Chinese with English abstract)

[16] Xu L-H(徐立华), Li D-Q(李大庆), Liu X-M(刘兴民), Qan D-S(钱大顺), Ni J-Z(倪金柱), Yang D-Y(杨德银). Study on the developmental mechanism of cotton bolls (Gossypium hirsutum L.) and the influencing factors. Acta Gossypii Sin (棉花学报), 1994, 6(4): 253-255 (in Chinese with English abstract)

[17] Zou Z-Q(邹宗晴), Pan Y-W(潘友旺), Wu G-R(吴国荣), Feng H-J(冯汉金), He X-P(何旭平), Leng S-F(冷苏凤), Cheng $\mathrm{H}-\mathrm{L}$ (承泓良). The expression of “Yumian 1" with high quality in near sea region. Jiangxi Cottons (江西棉花), 2001, 23(1): 34-35 (in Chinese)

[18] Zhu Y-G(朱永歌), Yu Q-S(俞全胜), Sun T-S(孙天曙), Ji C-L(纪 从亮), He X-P(何旭平), Chen D-H(陈德华), Wu Y-K(吴云康). The study of growth characters and cultural measures of "Yumian 1” with high quality. China Cotton (中国棉花), 2002, 29(3): 17-19 (in Chinese) 